\title{
Penicillum oxalicum spg1: A novel entomopathogenic fungus isolated from mummified Bemisia tabaci (Gennadius) of cotton
}

\author{
Sanjeev Kumar Kataria ${ }^{*}$, Paramjit Singh ${ }^{1}$, Gulab Pandove ${ }^{1}$, Anu Kalia ${ }^{2}$ and Ravinder \\ Singh Chandi ${ }^{2}$
}

${ }^{1}$ Punjab Agricultural University, Regional Research Station, Bathinda, Punjab, INDIA

${ }^{2}$ Electron Microscopy and Nano Science Laboratory, Department of Soil Science, Punjab Agricultural University, Ludhiana, INDIA

*Corresponding author. E-mail: k.sanjeev@pau.edu

Received: May 10, 2017; Revised received: August 3, 2017; Accepted: January 20, 2018

\begin{abstract}
Whitefly has assumed the status of a serious pest of cotton in north India in recent past due to its severe attack on cotton crop. The productivity of cotton crop has fallen substantially from $574 \mathrm{~kg} \mathrm{ha}^{-1}$ of lint in the year 2014 -15 to $197 \mathrm{~kg} \mathrm{ha}^{-1}$ in the year 2015-16 in Punjab. During extensive epidemiological surveillance of whitefly on cotton crop in the month of September 2016, mummified whiteflies with fungus were noticed on both abaxial and adaxial surfaces of leaves of the infested cotton plant at village, Mandi Khurd, Mansa District of Punjab, India and at Punjab Agricultural University, Regional Research Station, Bathinda, India. The fungus was isolated and purified from the mummified white fly and characterized at molecular level by sequencing 633 bp D2 region of Large Subunit (LSU) rRNA gene and identified as Penicillium oxalicum spg1. The gene sequence has been submitted to NCBI, USA with accession no. KY214238. The microscopic studies (stereo- and scanning electron) of the cotton leaves with mummified whitefly further strengthen the entomopathogenic potential of $P$. oxalicum spg1. There are few reports of entomopathogenic potential of $P$. oxalicum spg1 against other insects and pests. To our knowledge, this is the first report of isolation and identification of $P$. oxalicum spg1 from mummified white fly. It's potential as a biocontrol agent against white fly can be exploited in a promising way with nominal interference with biological equilibrium.
\end{abstract}

Keywords: Molecular characterization, P. oxalicum spg1, Surveillance, Whitefly

\section{INTRODUCTION}

Cotton (Gossypium hirsutum L.) is a leading fiber crop of India that contributes notably to Indian economy. In the year 2015, a devastating attack of cotton crop by white fly in Punjab's malwa region had affected about 2/3rd of standing crop (Anonymous, 2015). White fly is a polyphagous insect that infest several economically essential crops (Dubey and Ko, 2008). In India, whitefly was first reported on cotton at Pusa (Bihar) and designated as Bemisia gossypiperda $\mathrm{M}$. and L (Mishra and Lamba, 1929). The life cycle of B. tabaci includes six stages; the egg, the crawler ( $1^{\text {st }}$ instar $)$, two sessile nymphal instars $\left(2^{\text {nd }}\right.$ and $3^{\text {rd }}$ instar $)$, the puparium ( $4^{\text {th }}$ instar), and the adult or imago (David, 2012). The life cycle of whitefly get concluded in 24 to 44 days and it can complete at least 15 generations on cotton in Punjab (Aneja, 2000).

The white fly attack impairs cotton crop in two ways, essentially by sucking the sap and also by excreting honey dew on which sooty mould grows. Direct feeding reduces the photosynthetic activities of the plant and hence the yield. Lint contamination with honeydew associated fungi and through transmission of leaf curl virus disease results in incidental damage by white fly (Mohan et al., 2014).

In north India, the population of whitefly started increasing in the year 2012 but initially it was confined to Abhor and Fazilka districts of Punjab, India and Ganganagar district of Rajasthan, India. In the year 2015-16, its attack was severe in entire North India. Due to severe attack of whitefly, the productivity of cotton in Punjab declined from $574 \mathrm{~kg} \mathrm{ha}^{-1}$ of lint in 2014-15 to $197 \mathrm{~kg} \mathrm{ha}{ }^{\square}$ in 2015-16. This seriously affected the agricultural economy of the cotton growing districts of the Punjab state. The Government of Punjab, India had to distribute Rs. 735 crores to cotton growing farmers of the state as compensation.

The scientists of Punjab Agricultural University, Ludhiana, Punjab, India worked very hard collectively to curb the menace of whitefly through monitoring and surveillance of cotton crop throughout the season. During an extensive epidemiological surveillance of whitefly on cotton in the month of September, 2016 at Punjab Agricultural University, Regional Research Station, Bathinda India, mummified whiteflies were noticed on the cotton leaves and similar observations 
were recorded in village, Mandi Khurd, Mansa District (Fig. 1). The leaves of cotton plants on which mummified whiteflies were seen, were healthy, with apparently no infection of any other insect-pest. Keeping in view, the entomopathogenic potential of fungus the objective of present research was isolation and characterization of the potential entomopathogenic fungus. Further the complete identification of the isolate was also undertaken after requisite molecular characterization.

\section{MATERIALS AND METHODS}

Isolation of fungus from mummified whitefly: The mummified flies were collected in sterilized vials. The whole of mummified whitefly was transferred to potato dextrose agar (PDA) containing chloramphenicol to inhibit bacterial growth with the help of sterile platinum loop under sterilized conditions. The petriplates were sealed with para-film to reduce dehydration. The plates were incubated at $25^{\circ} \mathrm{C}$ and daily observations were made for 10 days. The emerged fungal biomass was picked up and transferred to fresh PDA medium for further investigations.

Morphological characterization of fungus: Macroscopic study was done by studying the colour texture and topography of colony using potato dextrose agar (PDA) as the standard medium at $25{ }^{\circ} \mathrm{C}$ for 5 days. Microscopic study of fungus was done by preparing slide stained with lacto-phenol cotton blue dye and observations were made under light microscope.

Molecular characterization: For molecular characterization of fungus, fungal mycelium was prepared from pure culture using $50 \mathrm{ml}$ of potato dextrose broth in $100 \mathrm{ml}$ conical flask and was incubated at $25 \pm 1^{\circ} \mathrm{C}$ for 7 days. Mycelia from $50 \mathrm{ml}$ broth were harvested by filtration through whatman sterile filter paper. DNA was isolated by xcelgen fungal gDNA isolation kit and quality was evaluated on $0.8 \%$ agarose gel, a single band of high-molecular weight DNA was recorded. Isolated DNA was amplified with D2 region Specific Primer (DF and DR) using Veriti ${ }^{\circledR} 99$ well thermal cycler (Model No. 9902). A single discrete PCR amplicon band of $700 \mathrm{bp}$ was observed (Fig. 2). The PCR amplicon was enzymatically purified and further sub-

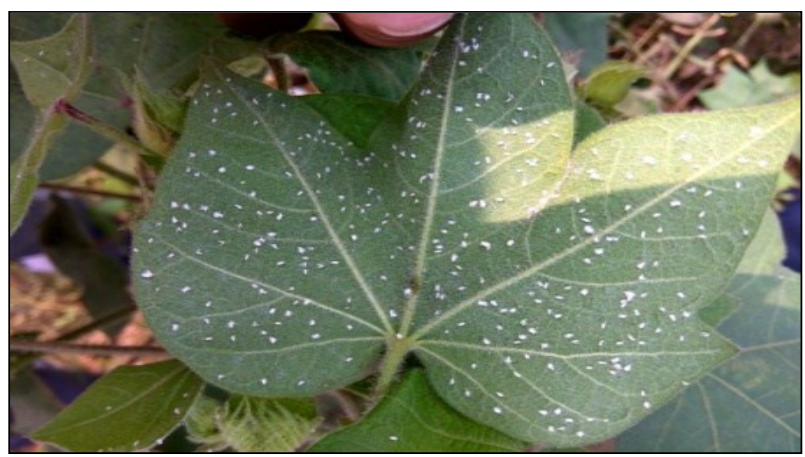

Fig. 1. Cotton plant leaf with mummified jected to Sanger Sequencing. Bi-directional DNA sequencing reaction of PCR amplicon was carried out with DF and DR primers using BDT v3.1 Cycle sequencing kit on ABI 3730xl Genetic Analyzer (Xcelris Labs Ltd., Premchand Nagar Road, Bodakdev, Ahmedabad 380054, India).

Stereo- and scanning electron microscopy (SEM) of the infested cotton leaf: Leaves with mummified whiteflies were also studied under stereomicroscope and SEM. Small discs of $(4 \times 4 \mathrm{~mm})$ were cut from the infested leaf sample and fixed in primary fixative for 24 hours. Later, the samples were placed in secondary fixative for 45 minutes followed by rinsing and dehydration. The dehydrated sample was sputtered with gold in ion sputter coater (model Hitachi E1010, Japan) and viewed in secondary imaging mode in SEM (model Hitachi s-3400N, Japan).

\section{RESULTS AND DISCUSSION}

White fly feed by penetrating the tissues of plants and sucking sap directly from the vascular bundles. It is not susceptible to bacteria and viruses that are customarily transmitted via host feeding on contaminated vegetation. Most entomopathogenic fungi infect their hosts by straight forward penetration of the body wall. These are amidst the most imperative natural attacker of whiteflies (Lacey et al., 1996). The fungus which was found on the mummified whiteflies present on leaves of cotton plant during epidemiological surveillance was subjected to macroscopic and microscopic studies followed by molecular characterization. Stereomicroscopic and SEM studies of leaves of cotton plant with mummified whiteflies cadavers were also carried out to study the entomopathogenic potential of fungi against whitefly.

Macroscopic and microscopic characterization: Macroscopic features of fungus on petriplate containing PDA media showed rapid growth. The fungal growth on PDA appeared as cottony white mycelia which turned greenish/ bluish in colour becoming powdery compact due to production of asexual conidiospores. The rear side of the colony appeared yellowish cream in colour on PDA media. The microscopic

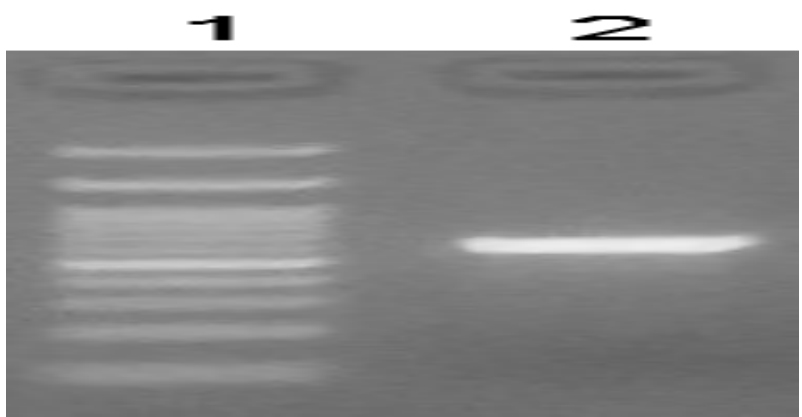

Fig. 2. $1.2 \%$ Agarose gel showing $700 \mathrm{bp}$ amplicon (D2 region) of $28 S$ rDNA. Lane 1: 100bp DNA Ladder and Lane 2: 700bp amplicon (D2 region) of $28 S \mathrm{rDNA}$. 


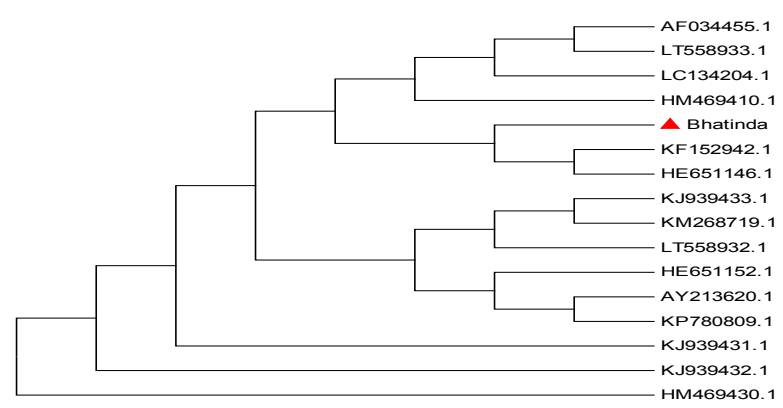

Fig. 3. Dendrogram showing the evolutionary relationship of the Penicillium oxalicum isolate.

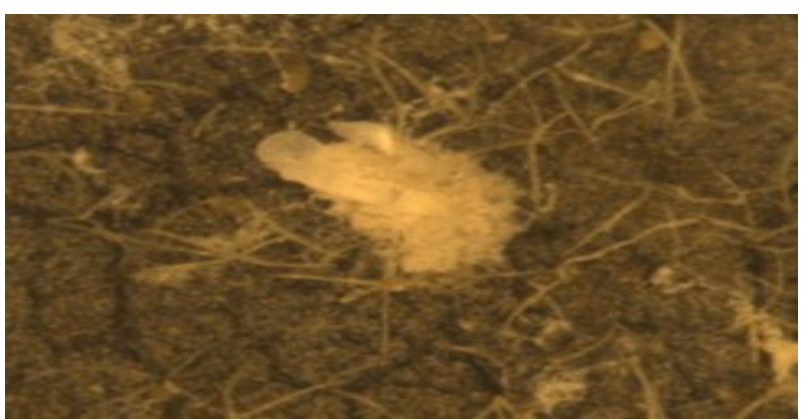

Fig. 4. Stereo micrograph showing fungal hyphae trailing on the surface of the cotton plant leaf.

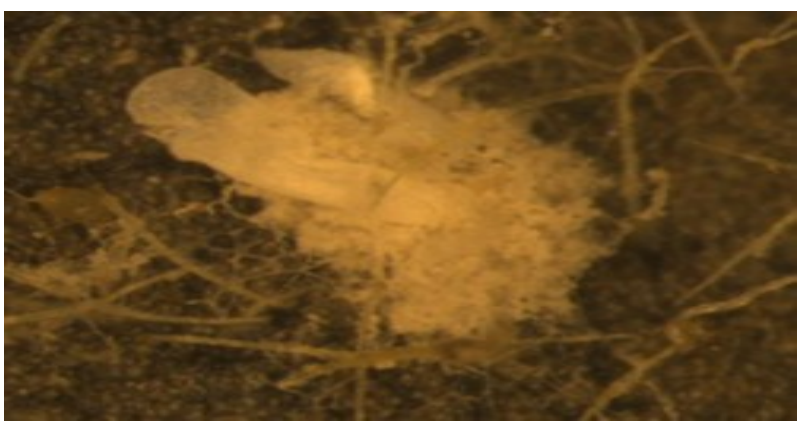

Fig. 5. Stereo micrograph showing P.oxalicum spg 1 mycelium growing on carcass of whitefly.

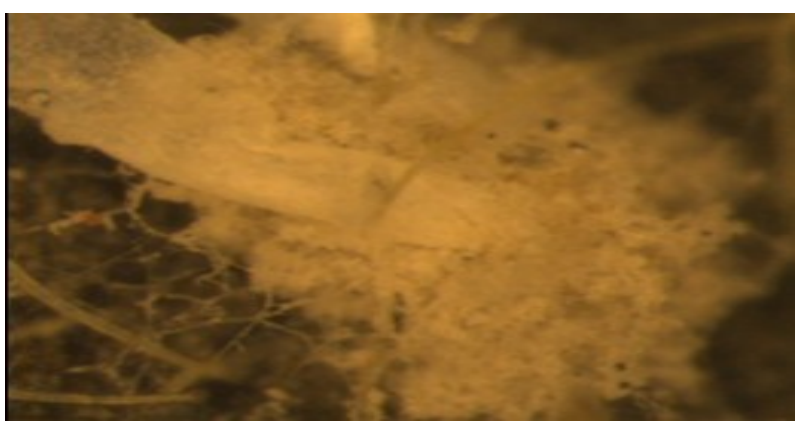

Fig. 6. Stereo micrograph showing P.oxalicum spg 1 mycelium growing on carcass of whitefly.

feature of fungus showed smooth hyphae, conidia with smooth wall in long chain.

Molecular Characterization: Consensus sequence of $633 \mathrm{bp}$ of D2 region of LSU gene was generated from forward and reverse sequence data using aligner software. The D2 region of $28 S \mathrm{rDNA}$ sequence was used

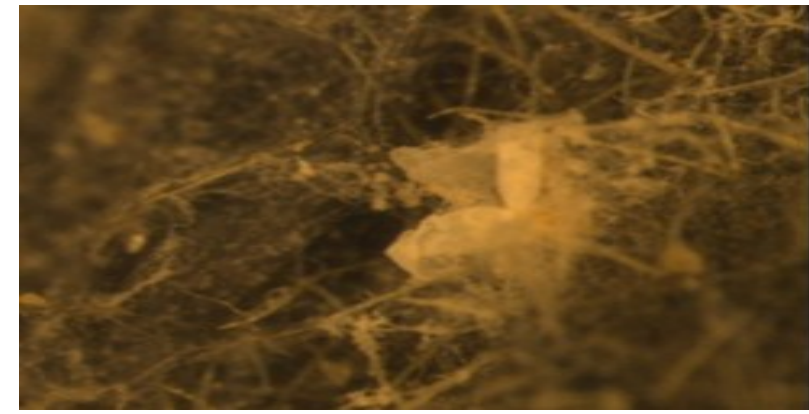

Fig. 7. Stereo micrograph showing completely degenerated cadaver of whitefly with only wings remains in the debris.

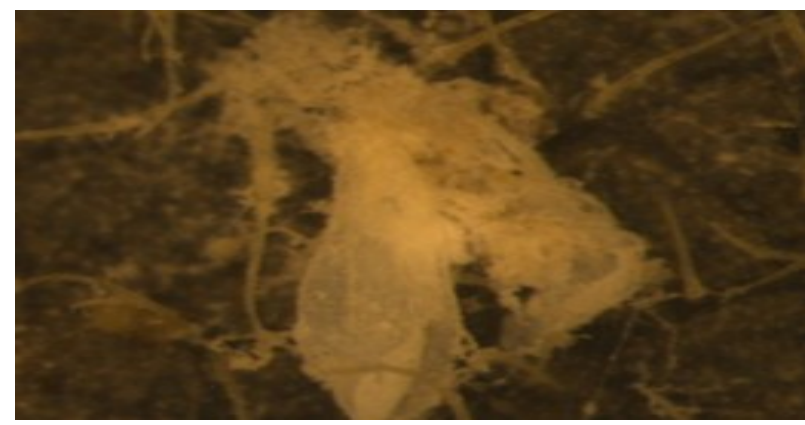

Fig. 8. Stereo micrograph showing completely degenerated cadaver of whitefly with only wings remains in the debris.

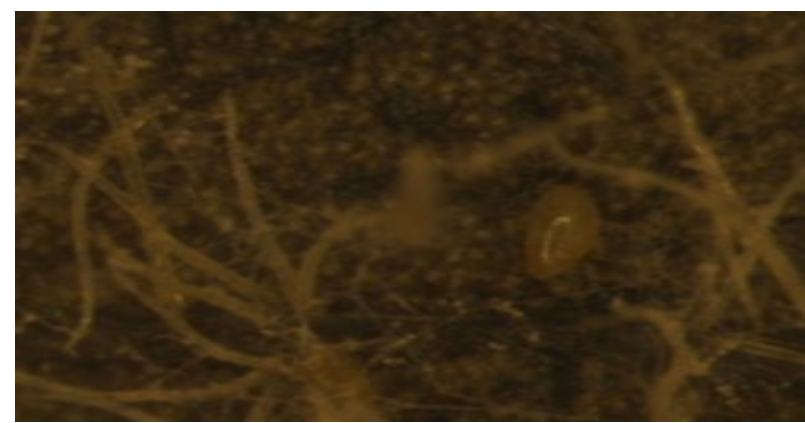

Fig. 9. Stereo micrograph showing the fungal network around the dull orange coloured egglaid on the surface of the cotton leaf.

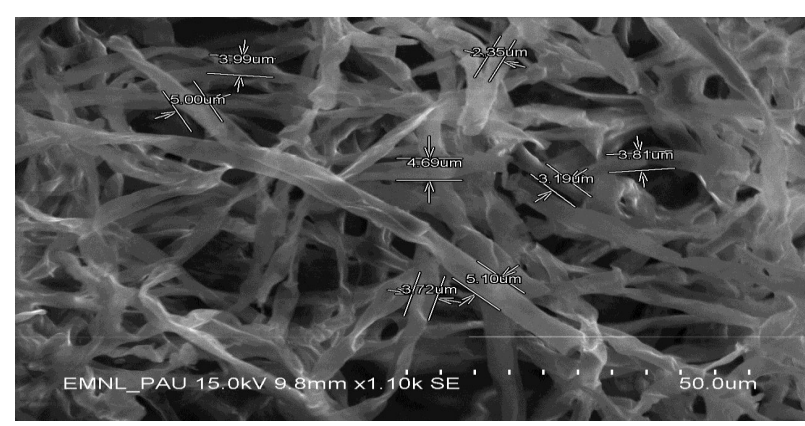

Fig. 10. Scanning electron micrograph of P. oxalicum spgl showing dense network of smooth and septate hyphae on the surface of cotton plant leaf (x 1100).

to carry out BLAST alignment search tool of NCBI Genbank database. Based on maximal identity score, first fifteen sequences were preferred and aligned using multiple alignment software program Clustal W. Distance matrix was generated using RDP database 
Sanjeev Kumar Kataria et al. / J. Appl. \& Nat. Sci. 10 (1): 138 - 143 (2018)

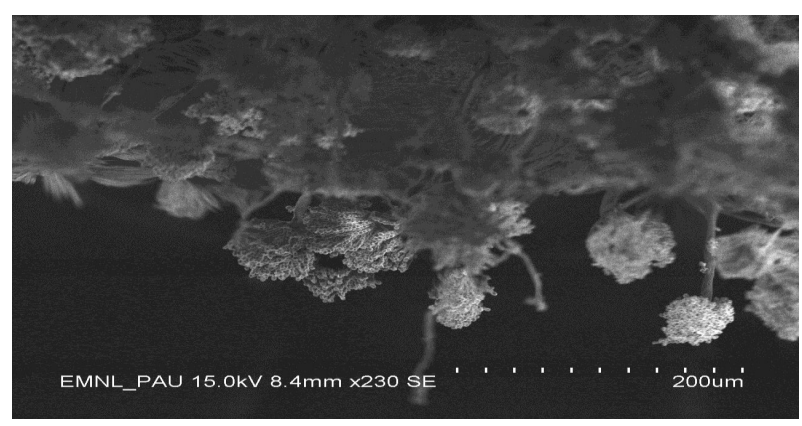

Fig. 11. Scanning electron micrograph of P. oxalicum spg1 showing conidiogenesis, conidia of fungus appear to be arranged in long chains (x230).

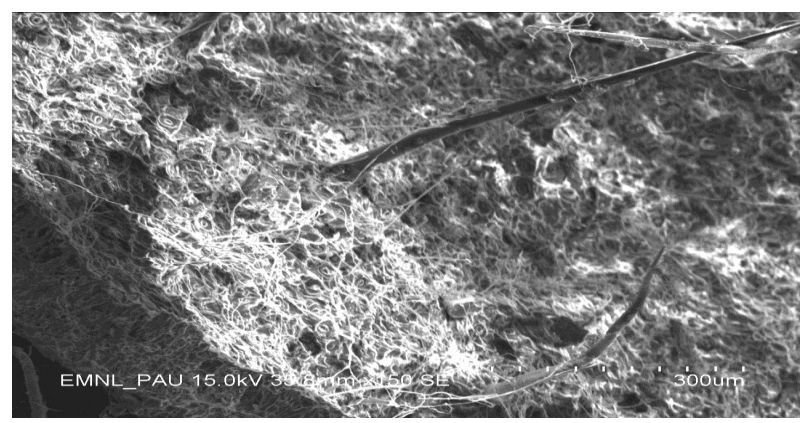

Fig. 12. Scanning electron micrograph of P. oxalicum spgl on the surface of cotton leaf showing hyphae of fungus climbing the trichome of cotton plant leaf.

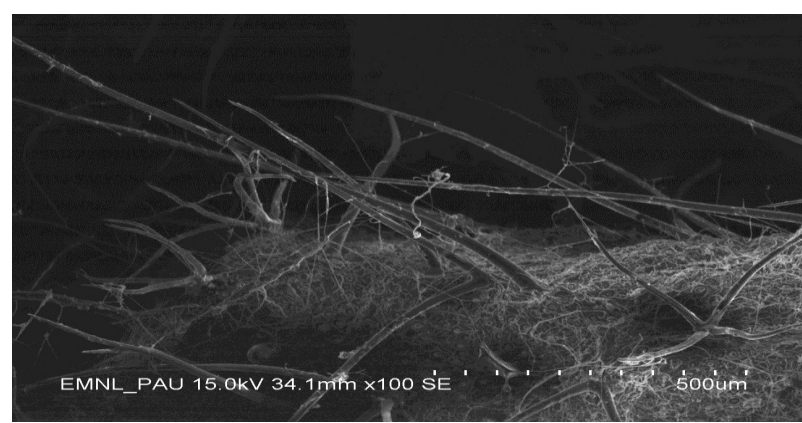

Fig. 13. Scanning electron micrograph showing vertical climbing hyphae of P. oxalicum spgl forming hyphal traplike structure by trailing over the trichomes of the cotton leaf (x100).

and the phylogenetic tree was composed using MEGA5 software algorithm. On the basis of nucleotide homology and phylogenetic analysis, the evolutionary history was inferred using the NeighborJoining method (Saitou and Nei, 1987). The bootstrap consensus tree inferred from 1000 replicates (Felsenstein, 1985) was taken to represent the evolutionary history of the taxa analyzed (Felsenstein, 1985). Branches corresponding to partitions reproduced in less than $50 \%$ bootstrap replicates were collapsed. The evolutionary distances were computed using the Jukes-Cantor method (Kimura, 1980) and were in the units of the number of base substitutions per site. The rate variation among sites was modelled with a gamma distribution (shape parameter $=1$ ). The

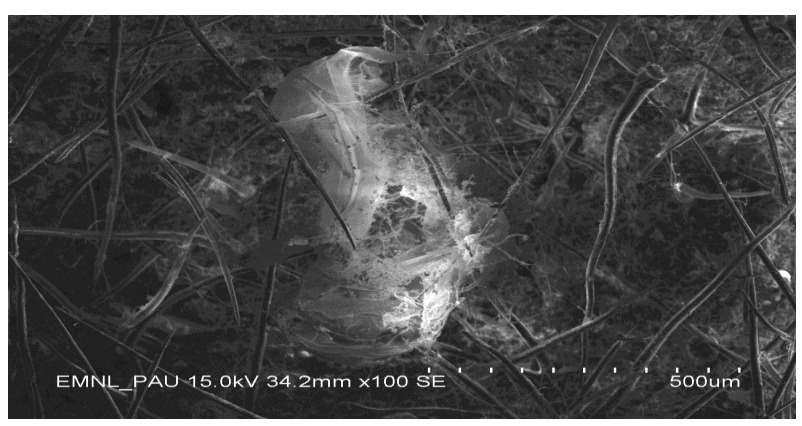

Fig. 14. Scanning electron micrograph of dead and decayed cadaver of the whitefly on surface of cotton plant leaf $(x 100)$

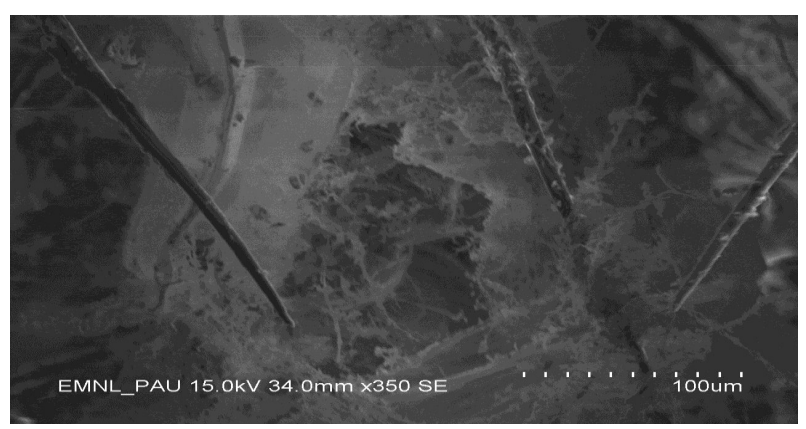

Fig. 15. Scanning electron micrograph of dead and decayed carcasses of the whitefly on surface of cotton leaf showing cuticle penetration, proliferation and colonization by hyphae of P. oxalicum spgl into the integument of whitefly cadaver (x350).

analysis involved 16 nucleotide sequences. Codon positions included were $1^{\text {st }}+2^{\text {nd }}+3^{\text {rd }}+$ Noncoding. All positions containing gaps and missing data were eliminated. There were a total of 588 positions in the final dataset. Evolutionary analyses were conducted in MEGA5 (Tamura et al., 2011). The fungus showed similarity with Penicillium oxalicum strain 114-2 (Accession Number: KF152942.1). Thus, identified as Penicillium oxalicum spg1, its gene sequence has been submitted to NCBI, USA with accession no. KY214238 (Fig. 3).

Virtually, scanty information is available on control of whitefly by use of $P$. oxalicum. $P$. oxalicum has been reported to be a pathogenic fungus of the aphid Ceratovacuna lanigera, an insect pest on sugarcane (Michereff et al., 1995). The volatile compounds produced from $P$. oxalicum have been reported to inhibit the growth of Glomerella cingulata (Pandey et al., 1993). The successful infection of any entomopathogenic fungi depends principally on the attachment and infiltration strength of a fungus to infect the insect integuments due to secretion of an array of extracellular enzymes (lipases, proteases and chitinases) that hydrolyze the epidermis of the insect (Shahid et al., 2012). Entomopathogenic fungi can also infect non-feeding stages, eggs and pupae since fungi do not have to be ingested by the target insect and can raid their hosts 
directly through the exoskeleton or cuticle (Hussain et al., 2012). The entomopathogenic fungi further resist insect immune system response by exploiting nutrient present in the haemocoel and cause pervasive tissue damage by production of toxin. Al-Keridis (2015) figured out the affect of Penicillium sp. to control the rust red beetle (Tribolium castaneum) by using different concentrations of fungal extract $(10,30,50 \%)$ and 40 $\%$ application of the whole fungal organ against insects. The $50 \%$ fungal extract was found to be most effective against red beetle.

The substantial use of insecticides have resulted in the development of insecticide defiance among organisms in addition the residue chemicals affect the human health. Therefore, an eco-friendly surrogate is needed to slash the negative effect of pesticides. Entomopathogenic fungi as bio-pesticides are influential natural regulators of insect populations and have potential as myco-insecticide agents against diverse insect pests in agriculture (Mazid et al., 2011).

Gindin et al. (1996) displayed the applicability of $V$. Lecanii (fungus) as an important element in biological control of aphids, whiteflies and thrips. Al-Ameri (2011) also marked the potency of Mycotal (commercial product) to control the all stages of $\mathrm{Be}$ misia tabaci when sprayed on plant eggplant.

Commercial production and application of biopesticides demands a few prerequisite such as viability for longer period of time, high tolerance to variable climatic conditions, abiotic stress associated with transportation, storage and application. In addition biopesticides should be cost effective, easy to handle, no adverse effects on seed germination and plant growth and should have wide range of effectiveness against multiple pathogens as well as formulations with long shelf life (De-Vrije et al., 2001).

Stereomicroscopic study of cotton leaf with mummified whiteflies: The stereomicroscopic study of the cotton leaves showed the occurrence of dead cadavers of whiteflies either mummified with white cottony fungal growth or completely decayed whitefly with only their wings remaining in the debris. This further provided a valuable insight for the entomopathogenic potential of $P$. oxalicum spg1 on whitefly. These images could also help to study the host-pathogen interaction for the first time to our knowledge in case of whitefly and $P$. oxalicum spg1. The fungal hyphae of $P$. oxalicum were observed to trail on the surface of cotton leave (Fig.4), and on the insect cadaver (Fig. 5 and 6) further causing decay of the pest body (Fig. 7 and 8) possibly due to production and secretion of hydrolytic enzymes by the fungus. Pareek et al. (2014) also reported enhanced production of chitin deacetylase by Penicillium oxalicum $\mathrm{SAE}_{\mathrm{M}}-51$ through response surface optimization of fermentation conditions. The network of fungus around the dull orange coloured egg laid on the surface of cotton leaf was also observed (Fig. 9).

Scanning electron microscopic (SEM) study of cotton leaf with mummified whiteflies: Scanning EM has frequently been used to study the mode of pathogenesis in host pest-pathogen interactions. These studies have helped in determining the virulence attributes of fungal strains and in identification of insect barriers to infection (Vestergaard et al. 1999). The fine morphology of $P$. oxalicum spg1 hyphae as observed in Fig.10 showed formation of dense network of mycelium on the surface of cotton leaf. The hyphae of fungus found to be smooth and septate. This isolate also exhibited formation of long chains of asexual spherical spores/ conidiospores on elongated head like conidiophores (Fig.11). The vertical trailing of hyphae of $P$. oxalicum spg1 on trichomes of cotton leaf helped in formation of a trap network-like structure (Fig. 12 and 13). The entrapment of the whitefly in this hyphaetrichome network followed by active infection by the entrailing hyphae on pest surface and tissue might have led to death of the pest (Fig. 14). The dead and decayed cadaver of whitefly on surface of cotton leaf showed the growth of $P$. oxalicum spg1. Moreover, the fungal hyphae can be observed growing in the body cavity of the dead whitefly (Fig. 15). These micrographs further strengthened and established the entomopathogenic potential of P.oxalicum spg1 against whitefly as biological control agent. Biological control with pathogenic fungi would be a promising alternative to chemical control. These finding also corroborated with the findings of Santamarina et al. (2002) who have extracted metabolites of P. oxalicum lineages and indicated their antagonistic effect against bacteria, fungi and insects. Santamarina et al. (2003) also showed biocontrol activity of Penicillium oxalicum agent against species of Fusarium. Sabuquillo et al. (2005) further reported Penicilium oxalicum Currie and Thom as a promising fungal agent for biological control of soilborne diseases of tomato. Application of a conidial suspension of $P$. oxalicum by watering the tomato seedlings in seedbeds 7 days before transplanting against Fusarium and Verticillium wilts of tomato plants has been reported by Larena et al. (2003).

\section{Conclusion}

P. oxalicum spg1, a novel fungal bio-control agent having entomopathogenic significance, could play a pragmatic role in integrated pest management. However, its practical utility as a potential biocontrol agent of whitefly will require standardization of the following parameters (i) Optimization of media for growth; (ii) Carrier for viable fungal spore suspension;(iii) Assay for the production of cuticle degrading enzymes (Chitinase, Chitosanase, Chitin deacetylase assay, Protease and Lipase assay); (iv) bioassay of different 
formulations under in vitro and in vivo conditions and (v) The animal and human pathogenic aspect of this culture is required to be probed. The use of Penicillium oxalicum spg 1 in any integrated pest management programme further need to be tested, until proven safe for natural enemies and non-target organisms.

\section{ACKNOWLEDGEMENTS}

We express our gratitude to Punjab Agricultural University, Ludhiana, India for the financial support under the project entitled "Cotton Development Programme in Punjab". Authors are also thankful to Head, Department of Soil Science, Punjab Agricultural University to provide necessary infrastructural facilities for scanning electron microscopy studies.

\section{REFERENCES}

Anonymous (2015). Times of India, dated October, 2015

Al-Ameri, D. T. (2011). Efficacy of the entomopathogenic fungus Beauveria bassiana and the commercial formulation of the fungus Lecanicillium muscarium (Mycotal) for the control of the cotton whitefly Bemisia tabaci, M. Sc. University of Baghdad- College of Agriculture.66 p.

Al-Keridis, L. A. (2015). Application of Penicillium sp as Entomopathogenic Fungi to Control the Red Rust Beetle Tribolium castaneum (Hbst.) (Coleoptera: Tenebrionidae). Biosci. Biotech. Res. Asia, 12: (spl.edn.2).

Aneja, A. K. (2000). Studies on the biology of cotton whitefly, Bemisia tabaci (Genn.) on American cotton Gossypium hirsutum (Linn.), M.Sc. Thesis, Punjab Agricultural University, Ludhiana, India.

David, V. (2012). The whitefly or mealywing bugs. Lambert Academic Publishing, Saarbrucken. Germany, 411

De-Vrije, T., Antoine, N., Buitelaar, R. M., Bruckner, S., Dissevelt, M., Durand, A., Gerlagh, M., Jones, E. E., Lut,h P., Oostra, J., Ravenberg, W. J., Renaud, R., Rinzema, A., Weber, F. J. and Whipps, J. M. (2001). The fungal biocontrol agent Coniothyrium minitans: production by solid-state fermentation, application and marketing. Appl. Microbiol.Biotechnol., 56:58-68.

Dubey, A.K. and Ko, C.C. (2008). Whitefly (Aleyrodidae) host plants list from India. Orient. Insects, 42: 49-102.

Felsenstein, J. (1985). Confidence limits on phylogenies: An approach using the bootstrap. Evolution, 39:783-791.

Gindin, G., Barash, I., Raccah, B., Singer, S., Benzeev, I. and Klein. (1996). The potential of some entomopathogenic fungi as Biocontrol against onion thrips, Thrips tabaci and western flower thrips Frankliniella accidentalis. Folia Entomology, Lvll: 37-42.

Hussain, A., Tian, M., Ahmed, S. and Shahid, M. (2012). Current Status of Entomopathogenic Fungi as Mycoinecticides and Their Inexpensive Development in Liquid Cultures, from Zoology. Edited by Dr. MaríaDolores García (Ed.), InTech, 103-122.

Kimura, M. (1980). A simple method for estimating evolutionary rate of base substitutions through comparative studies of nucleotide sequences. J. Mol. Evol.16:111-120.

Lacey, L. A., Fransen, J. J. and Carruthers, R. (1996). Global distribution of naturally occurring fungi of Bemisia, their biologies and use as biological control agents, In: Bemisia 1995: Taxonomy, Biology, Damage Con- trol and Management, Gerling D, Mayer RT, eds. Intercept Ltd., Andover, U.K., pp. 401-433.

Larena, I., Melgarejo, P. and De Cal, A. (2003). Drying of conidia of Penicillium oxalicum, a biological control agent against Fusarium wilt of tomato. J.Phytopathol., 151:600-606.

Mazid, S., Rajkhowa, R. C. and Kalita, J. C. (2011). A review on the use of biopesticides in insect pest management. Int. J.Sci. Adv. Technol.,1:169-178.

Michereff, S. J., Silveira, N. S. S., Reis, A. and Mariano, L. R. (1995). Greenhouse screening of Trichoderma isolates for control of Curvularia leaf spot of yam. Mycopathologia, $130: 103-108$.

Mishra, C. S. and Lamba, K. S. (1929). The cotton whitefly (Bemisia gossypiperda). Bulletin Agricultural Research, Pusa, 196:7.

Mohan, S., Monga, D., Kumar, R., Nagrare, V., Nandini G.N., Vennila, Tanwar, R. K.,Sharma, O. P., Bhagat, S., Agarwal, M., Chattopadhyay, K.R., Birah, A., Amaresan, Singh, A., Sushil, S. N., Ram Asre, Kapoor, K. S., Jeyakumar, P. and Satyagopal, K. (2014). Integrated pest management Package for cotton.

Pandey, R. R., Arora D. K. and Dubey, R. C. (1993). Antagonistic interactions between fungal pathogens and phyllophane fungi of guava. Mycopathologia, 124:31-39.

Pareek, N., Ghosh, S., Singh, R. P. and Vivekanand, V. (2014). Enhanced production of chitin deacetylase by Penicillium oxalicum $\mathrm{SAE}_{\mathrm{M}^{-}}-51$ through response surface optimization of fermentation conditions. Biotech, 4:33-39.

Sabuquillo, P.,De Cal A. and Melgarejo P. (2005). Dispersal improvement of a powder formulation of Penicillium oxalicum, a biocontrol agent of tomato wilt. Plant Dis., 89:1317-1323

Saitou, N. and Nei, M. (1987). The neighbor-joining method: A new method for reconstructing phylogenetic trees. Mol. Biol. Evol.,4:406-425.

Santamarina, M. P., Rosello, J., Llacer, R. and Sanchis, V. (2002). Antagonistic activity of Penicillium oxalicum Corrie and Thom, Penicillium decumbens Thom and Trichoderma harzianum Rifai isolates against fungi, bacteria and insects in vitro. Rev. Iberoam. Micol., 19:99-103.

Santamarina, S. M. P., Rosello, C. J., Barcelo, C. S. and Marin, S. S. (2003). Effect of water activity and temperature on competing abilities of Penicillium oxalicum against Fusarium oxysporum. Rev. Iberoam. Micol., 20:154-159.

Shahid, A. A., Rao, A., Bakhsh, A. and Husnain, T. (2012). Entomopathogenic fungi as biological controllers: New insights into their virulence and pathogenicity. Arch. Biol Sci. Belgrade.64: 21-42.

Tamura, K., Peterson, D., Peterson, N., Stecher, G., Nei, M. and Kumar, S. (2011). MEGA5: Molecular Evolutionary Genetics Analysis using Maximum Likelihood, Evolutionary Distance, and Maximum Parsimony Methods. Mol. Biol. Evol., 28:2731-2739.

Vestergaard, S., Butt, T. M., Bresciani, J., Gillespie, A. T. and Eilenberg, J. (1999). Light and electron microscopy studies of the infection of the western flower thrips Frankliniellaoccidentalis (thysanoptera:thripidae) by the entomopathogenic fungus Metarhizium anisopliae. J. Invertebr.Pathol.73:25-33. 